for females to have higher rates when the presence of suicidal intent is required. If this were the case, it might help to explain how Isometsä \& Lönnqvist found a higher proportion of female suicides with previous suicide attempts.

Unfortunately, the issue of definition in suicidology continues to provoke controversy. The lack of standardisation limits our ability to make comparisons and generalisations based on the research findings of others, whether from the same jurisdiction or not.

Hawton, K., Fagg, J., Simkin, S., et al (1997) Trends in deliberate self-harm in Oxford, 1985-1995. Implications for clinical services and the prevention of suicide. British Journal of Psychiatry, I7I, 556-560.

Isometsä, E. \& Lönnqvist, J. (1999) Suicide attempts deliberate self-harm (authors' reply). British Journal of Psychiatry, 175, 90

Kerkhof, A. J. F. M., Schmidtke, A., Bille-Brahe, U. et al (eds) (1994) Attempted Suicide in Europe: Findings from the Multicentre Study on Parasuicide by the WHO Regional Office for Europe, p. 7. Leiden: DSWO Press.

Ogundipe, L. O. (1999) Suicide attempts v. deliberate self-harm (letter). British Journal of Psychiatry, I75, 90.

M. Lawlor, P. Corcoran, D. Chambers

National Suicide Research Foundation, I Perrott

Avenue, College Road, Cork, Ireland

\section{Post-abortion mania}

I was interested to read the report by $\mathrm{Dr}$ Mahe and his colleagues, describing a woman who suffered from five episodes of puerperal mania and two of post-abortion psychosis, one after a therapeutic abortion and one after a spontaneous abortion. This clinical observation is a valuable contribution to the literature.

The association of acute psychosis with abortion in women susceptible to puerperal psychosis has previously been noted in nine reports, starting with Esquirol in 1819. Some of the terminations were carried out in order to prevent a puerpera psychosis! This literature is summarised in my book Motherhood \& Mental Health, pages 91-93. There is evidence, especially from Denmark (David, 1985), that abortion is a greater risk factor than a full-term pregnancy.

Brockington, I. F. (1996) Motherhood \& Mental Health Oxford: Oxford University Press.

David, H. P. (1985) Post-abortion and post-partum psychiatric hospitalization. In Abortion: Medical Progress and Social Implications. CIBA Foundation Symposium II5, pp. 150-164. Chichester: Wiley.
Mahe, V., Nartowski, J., Montagnon, F., et al (1999)

Psychosis with gonadorelin agonist administration (letter). British Journal of Psychiatry, 175, 290-291.

I. F. Brockington Division of Neuroscience,

Department of Psychiatry, Queen Elizabeth

Psychiatric Hospital, Mindelsohn Way, Birmingham BI5 2QZ

\section{Cognitive effects of antipsychotics in schizophrenia and relationship to quality of life}

In his overview on cognitive effects of antipsychotics in schizophrenia Sharma (1999) stresses a relationship between cognitive function in schizophrenia and quality of life as an outcome measure. I think that Sharma's use of the concept 'quality of life' has to be clarified to prevent a number of rather common biases. $\mathrm{He}$ quotes two studies that are said to support a relationship between cognitive function in schizophrenia and quality of life (Davidson \& Keefe, 1995; Green, 1996). The term quality of life is not operationalised in the first study. In the second study, which is in fact an overview of other studies, it is reported by Heinrichs' Quality of Life Scale (Heinrichs et al, 1984). Like most other instruments which have been used to detect the effect of atypical neuroleptics on quality of life in schizophrenia (Priebe et al, 1999) the Quality of Life Scale (subtitled "An instrument for rating the schizophrenia deficit syndrome") assesses clinical judgements of negative symptoms of schizophrenia rather than subjective appraisals of quality of life made by the patient. As it seems reasonable to assume at least a moderate relationship of negative symptoms and cognitive functions in schizophrenia, it is not surprising that a relationship is found between cognitive functioning and quality of life when the quality of life measures seem to be confounded to a considerable extent by psychiatric symptomatology.

We think that it is necessary to make a distinction between quality of life as an evaluation criterion for illness-related phenomena (negative symptoms), and quality of life as a subjective assessment by the patient as a "subjective evaluation of oneself and one's social and material world" (Orley et $a l, 1998)$ - that is, subjective quality of life, not as a disease but as a generic concept. Since there are some studies that show that cognitive functioning in schizophrenia may predict social outcome, and since objective social outcome is moderately (although surprisingly weakly) associated with generic subjective quality of life, some association between cognitive functioning and subjective quality of life is conceivable, but has not yet been supported by empirical evidence.

In a validation study of a German short form of the Lancashire Quality of Life Profile (Kaiser et al, 1999), equivalent to the English short form of the instrument MANSA (see Priebe et al, 1999), we did not find any significant correlation between any of the categories of the Wisconsin Card Sorting Test (WCST; Heaton et al, 1993) (number of categories, perserverative errors and responses, etc.) and the mean value of all satisfactions ratings, satisfaction with life as a whole and with satisfaction with mental health in a carefully selected sample of out-patients with DSM-III-R schizophrenia (American Psychiatric Association, $1987 ; n=36$; mean age $=47$ years; mean illness duration $=19$ years). Our conclusion so far is that whether or not subjective quality of life is related to cognitive deficits in schizophrenia (in attention or memory, besides deficits in executive functioning, which are seen on a variety of tasks, most notably the WCST) remains unclear and so far is only a hypothesis, although it is widespread as an advertising slogan for atypical antipsychotic medication.

American Psychiatric Association (1987) Diagnostic and Statistical Manual of Mental Disorders (3rd edn, revised) (DSM-III-R). Washington, DC: APA

Davidson, M. \& Keefe, R. S. E. (1995) Cognitive impairment as a target for pharmacological treatment in schizophrenia. Schizophrenia Research, 17, 123-129.

Green, M. F. (1996) What are the functiona consequences of neurocognitive deficits in schizophrenia? American Journal of Psychiatry, 153, 32I-330.

Heaton, R. K., Chelune, G. J., Talley, J., et al (1993) Wisconsin Card Sorting Test Manual - Revised and Expanded. Odessa, FL: Psychological Assessment Resources.

Heinrichs, D. W., Hanlon, T. E. \& Carpenter, W. T. Jr (1984) The Quality of Life Scale: an instrument for rating the schizophrenia syndrome. Schizophrenia Bulletin, 10, 388-398.

Kaiser, W., Isermann, M., Hoffmann, K., et al (1999) A short assessment of subjective quality of life. Application and results of a short form of the Berliner Lebensqualitätsprofil (BELP-KF) (in German) Fortschritte der Neurologie und Psychiatrie, 67, 4I3-425.

Orley, J., Saxena, S. \& Herman, H. (1998) Quality of life and mental illness. Reflections from the perspective of WHOQOL. British Journal of Psychiatry, 172, 291-293.

Priebe, S., Oliver, J. P. J. \& Kaiser, W. (eds) (1999) Quality of Life and Mental Health Care. Petersfield: Wrightson Biomedical. 